\title{
Common Antigens of Streptococcal and Non-streptococcal Oral Bacteria: Isolation and Biochemical Characterization of the Extracellular Protein Antigen
}

\author{
By MARIE SCHÖLLER*, J. PAUL KLEIN, PASCAL SOMMER AND \\ ROBERT FRANK \\ Groupe de Recherches, INSERM U 157 Faculté de Chirurgie Dentaire, 67000 Strasbourg, \\ France
}

(Received 12 October 1981; revised 8 February 1982)

\begin{abstract}
An extracellular soluble common protein (ECP) has been purified from extracellular soluble fractions of exponential phase cultures of Streptococcus sanguis OMZ9, of a representative strain of each of Bratthall's seven serological groups of Streptococcus mutans, and of one strain each of Lactobacillus salivarius and Actinomyces viscosus. The ECP antigens from the different strains were prepared from SDS-dissociated immunoprecipitates by affinity chromatography on an anti-rabbit immunoglobulin column. The identity of such purified ECP antigens was demonstrated by their behaviour in immunodiffusion analysis, in SDS-PAGE, in which an identical molecular weight $(60000)$ was found, and by virtue of their similar amino acid and sugar compositions. This common antigen (ECP) consisted of $90 \%$ protein and $10 \%$ sugar.
\end{abstract}

\section{INTRODUCTION}

Streptococcus mutans, an important bacterium in the aetiology of dental caries, has been immunologically grouped into seven serotypes, $a$ to $g$ (Bratthall, 1970; Perch et al., 1974). The serotype antigens have been characterized as wall-associated polysaccharides, and have been extensively studied by several investigators (Burgess \& Edwards, 1973; Iacono et al., 1975; Wetherell \& Bleiweis, 1978; Brown \& Bleiweis, 1979; Hamada \& Slade, 1980). However, very little is known about the surface proteins of $S$. mutans strains. Mukasa \& Slade (1973) found that certain proteins were simultaneously extracted with the group antigen of $S$. mutans FA-1 by treatment with cold trichloroacetic acid or lysozyme. Several $S$. mutans strains were found to possess protein antigens which appeared to bind more or less strongly to cell walls (Russell, 1979; Nesbitt et al., 1980). Thus, glucosyltransferase as well as dextran-binding proteins were found to be associated with the cell surface of $S$. mutans (Kelstrup \& Funder-Nielsen, 1974; Kuramitsu \& Ingersoll, 1978). Examination of culture supernatants and cell wall extracts of $S$. mutans serotype $c$ showed the presence of at least four proteins (I to IV), in addition to the serotype antigen (Russell \& Lehner, 1978). Some of these proteins were shown to be common to other serological groups of $S$. mutans (Russell et al., 1980a).

In a previous investigation of the antigenic structure of $S$. sanguis OMZ9 we reported the existence of at least three extracellular soluble antigens (ESA) present in culture fluids and common to different oral bacteria including strains representative of each serological group of $S$. mutans, and a strain each of Actinomyces viscosus and Lactobacillus salivarius (Schöller et al., 1981). Two of these antigens were also present on the cell surface of all bacteria tested. The third antigen was only found in the cell-free culture supernatant and was identified as a soluble protein common to all bacterial species studied. This extracellular common protein (ECP) has

Abbreviations: ECP, extracellular common protein; ESA, extracellular soluble antigen; PBS phosphatebuffered saline: WEA, wall-associated antigen. 
now been purified from $S$. sanguis, $S$. mutans, $A$. viscosus and $L$. salivarius culture supernatants. Isolation and purification of ECP antigen was performed by dissociation of the antibodyantigen complexes followed by an affinity chromatography step. This paper describes these procedures, together with a biochemical comparative analysis of the protein purified from each strain.

\section{METHODS}

Organisms. The following strains, S. sanguis OMZ9, S. mutans strains E49 (serotype $a$ ), OMZ51 (b), OMZ70 (c) OMZ176 $(d)$, B-2 $(e)$, OMZ175 $(f)$ and KIR $(g), L$. salivarius ATCC 11741 and $A$. viscosus OMZ104, were described previously (Schöller et al., 1981). Strains were maintained in Brain Heart Infusion Broth (BHI, Difco).

Antigen preparation. Antigens were prepared from exponential phase cultures grown in synthetic medium D1-20 (Carlsson 1972). Extracellular soluble antigens were precipitated from culture supernatants with ammonium sulphate at $90 \%$ saturation and then desalted on a Bio-Gel P6 column (Bio-Rad). Wall-associated antigens (WEA) were extracted from the bacterial pellet with $0.5 \mathrm{M}$-phosphate buffer $\mathrm{pH} 6.0$ (Schöller et al., 1981).

Heat-killed $S$. sanguis cells were prepared from cells grown in BHI supplemented with glucose, according to the technique described by McCabe \& Smith (1973).

Antisera. Antisera against ESA and WEA from $S$. sanguis were raised in rabbits by administering four subcutaneous injections of an equal mixture of antigens and Freund's incomplete adjuvant at $10 \mathrm{~d}$ intervals (Schöller et al., 1981); animals were bled $10 \mathrm{~d}$ after the last injection. After ammonium sulphate precipitation at $50 \%$ saturation, the IgG fraction of anti-ESA gamma globulin was obtained by chromatography on protein ASepharose CL4B $(5 \times 1 \mathrm{~cm})($ Pharmacia) equilibrated with 0.1 M-phosphate buffer $\mathrm{pH} 7 \cdot 2$. The IgG fraction was eluted in the second peak with $0.2 \mathrm{M}$-glycine/ $\mathrm{HCl}$ buffer $\mathrm{pH} 2 \cdot 2$ (Ey et al., 1978).

Sheep IgG (Institut Pasteur Production, Paris) directed against rabbit immunoglobulins were also prepared by chromatography on protein A-Sepharose. Sheep IgG $(30 \mathrm{mg})$ was coupled to CNBr-activated Sepharose 4B (Pharmacia) as described by the manufacturers. The immunosorbant was packed into a column $(5 \times 1 \mathrm{~cm})$ and equilibrated with phosphate-buffered saline (PBS).

Preparation and dissociation of immune complexes. Anti-S. sanguis ESA IgG was first absorbed with $S$. sanguis heat-killed cells and then with $S$. sanguis WEA to eliminate the cross-reactive antigens, as previously described (Schöller et al., 1981). In immunodiffusion, the double cross-absorbed IgG fraction thus obtained gave only one precipitin band common to all bacterial species and was further used for antigen purification.

The extracellular common protein was purified from immune complexes by mixing ESA from each bacterial strain with anti-S. sanguis ESA cross-absorbed IgG fraction. The equivalence point for antigen-antibody precipitation was determined by reacting together several dilutions of antigen and antibody in ID tests. Concentrations of antigen and antibody corresponding to the equivalence point were then used to prepare immunoprecipitates. After incubation for $1 \mathrm{~h}$ at $25^{\circ} \mathrm{C}$ to avoid absorption of non-specific IgG, the immunoprecipitate was sedimented $\left(20 \mathrm{~min}, 10000 \mathrm{~g}, 4^{\circ} \mathrm{C}\right.$ ) and washed twice with PBS. The washed complexes were suspended in $100 \mu$ lectrophoresis buffer containing various dissociating agents, mixed for $10 \mathrm{~min}$ and submitted to PAGE. Various concentrations of Triton X-100, SDS and urea were tested for their ability to dissociate the immune complexes.

Antigen purification. The ECP antigen was purified from immune complexes obtained by mixing $10 \mathrm{ml}$ ESA from each bacterial strain with $10 \mathrm{ml}$ of the anti-ESA absorbed IgG fraction. After sedimentation and washing, the immune complexes were dissociated in a minimal volume $(0.5 \mathrm{ml})$ of PBS containing $0.5 \%$ SDS, boiled for 3 min and immediately diluted 50-fold with cold PBS. The diluted samples were applied to the sheep anti-rabbit immunoglobulin immunosorbant and eluted with PBS at a flow rate of $20 \mathrm{ml} \mathrm{h}^{-1}$. Fractions of $5 \mathrm{ml}$ were collected until $\boldsymbol{A}_{280}$ was lower than 0.02 . The column could be used again after elution with $0.2 \mathrm{M}$-glycine/ $\mathrm{HCl}$ buffer $\mathrm{pH} 2 \cdot 2$ and equilibration with PBS.

Analytical methods. The total carbohydrate content was evaluated by the anthrone method of Morris (1948) with D-glucose as a standard. Protein concentration was measured by the Lowry procedure with bovine serum albumin as a standard.

Amino analysis was carried out on ECP purified by affinity chromatography. ECP from each strain was hydrolysed in $6 \mathrm{M}-\mathrm{HCl}$ at $110^{\circ} \mathrm{C}$ for $24 \mathrm{~h}$ under vacuum and then analysed with a Beckman Instruments model $119 \mathrm{CL}$ analyser. Cysteine was measured as cysteic acid after performic oxidation.

Samples were subjected to methanolysis with methanol $/ 0.5 \mathrm{M}-\mathrm{HCl}$ under reflux during $24 \mathrm{~h}$; liberated sugars were submitted to trimethylsilylation and subjected to GLC on a Hewlett-Packard 7620A chromatograph with a flame ionization detector on a silicone OV17 column. Derivatives were separated on an Inox column $(4 \mathrm{~m})$ containing the following stationary phase: Chromosorb 80-100 mesh, WAD-DMCS 3\%, and silicone OV17, employing a linear temperature gradient of $115-200^{\circ} \mathrm{C}$ at $4{ }^{\circ} \mathrm{C} \mathrm{min}-1$; the carrier nitrogen flow was $20 \mathrm{ml} \mathrm{min}^{-1}$.

The effectiveness of antigen-antibody dissociation was checked by PAGE according to the method of Davis (1964), in the presence of $0 \cdot 1 \%$ Triton X-100, $0 \cdot 1 \%$ SDS or 6 M-urea. Gels were scanned in a Beckman Acta CII 
Spectrophotometer. SDS-PAGE was done by the method of Weber \& Osborn (1969), with $7.5 \%$ (w/v) polyacrylamide gels. Prior to electrophoresis, the different samples were treated for $5 \mathrm{~min}$ at $100{ }^{\circ} \mathrm{C}$ in the presence of $1 \%$ SDS. Molecular weights were estimated by co-electrophoresis of ECP samples with standard proteins (electrophoresis calibration kit, Pharmacia). Immunodiffusion was performed in $1 \%(\mathrm{w} / \mathrm{v})$ agarose (Ouchterlony, 1958).

\section{RESULTS}

\section{Immune complex dissociation}

It has been observed previously that the ESA fraction obtained from representative strains of the different serotypes of $S$. mutans, as well as from L. salivarius and A. viscosus, contained a single common protein antigen (ECP), which reacted with $S$. sanguis ESA antiserum that was absorbed with both whole cells and WEA. The ECP antigen appeared to be selectively excreted during bacterial growth (Schöller et al., 1981). Attempts were made to use the immunoprecipitates thus obtained to purify ECP. Dissociation of antigen-antibody complexes was achieved with all reagents tested [Triton X-100, $1 \%(\mathrm{v} / \mathrm{v})$; SDS, 0.5 to $1 \%(\mathrm{w} / \mathrm{v})$; and urea, $6 \mathrm{M}$ ].

A mixture of proteins (Fig. 1) was obtained with all three dissociating procedures. However, maximal dissociation was obtained by $0.5 \%$ SDS as judged by PAGE analysis of the immunoprecipitates (Fig. 1, C) and was used throughout this study. In these profiles, the ECP was not resolved from IgG heavy chain, but was well separated from IgG light chain.

\section{Purification of the ECP antigen}

Immunoprecipitates were prepared from each strain by mixing $10 \mathrm{ml} \mathrm{ESA}\left(2 \mathrm{mg} \mathrm{ml}^{-1}\right)$ with $10 \mathrm{ml}$ of the rabbit IgG fraction at the required concentration. Antigen-antibody complexes, after dissociation were immediately diluted 50 -fold and applied to a column containing immobilized sheep anti-rabbit IgG : rabbit IgG was retained, whereas the ECP antigen passed through with the starting buffer (PBS). ECP antigens were dialysed against 10-fold diluted PBS and concentrated by lyophilization to a final protein concentration of $1 \mathrm{mg} \mathrm{ml}^{-1}$.

The purity of the ECP antigens prepared from each strain by affinity chromatography was checked by gel electrophoresis and by immunodiffusion. The electrophoresis pattern of ECP antigens from different strains showed a single band of Coomassie brilliant blue positive

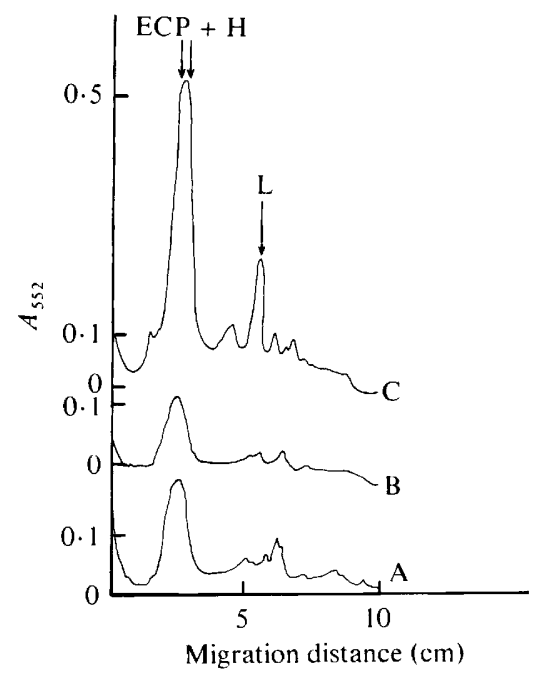

Fig. 1. Electrophoretic pattern of $S$. sanguis OMZ9 immunoprecipitates analysed according to Davis (1964). Precipitates were obtained by mixing $S$. sanguis OMZ9 ESA with absorbed anti-ESA IgG (see Methods). The complexes were dissolved in $6 \mathrm{M}$-urea (A), $1 \%$ (v/v) Triton X-100 (B), or 0.5\% (w/v) SDS (C). Scans of Coomassie blue stained gels are shown. ECP, extracellular common protein; H, IgG heavy chains; L, IgG light chains. 


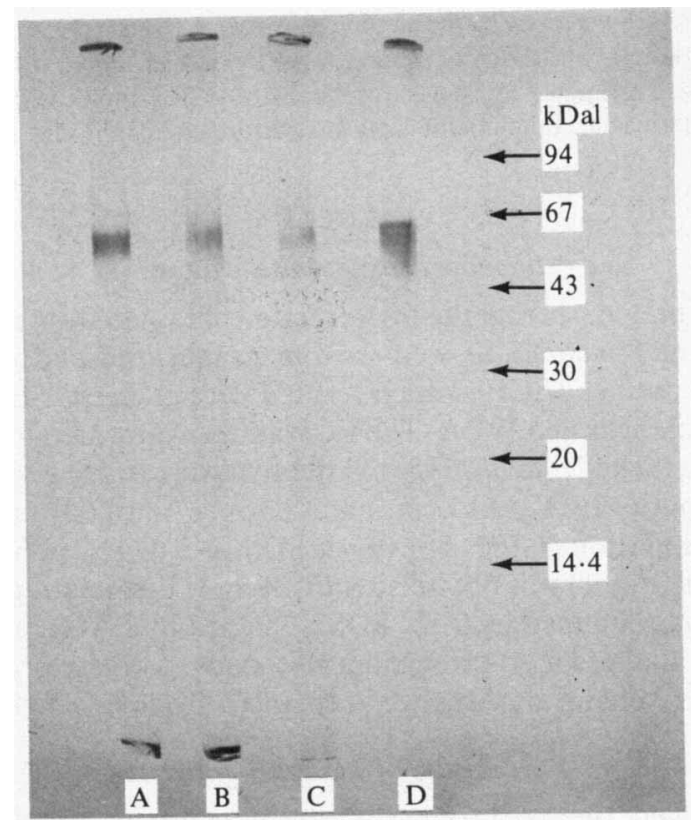

Fig. 2. SDS-PAGE of samples of purified ECP from the following strains: A, S. sanguis OMZ9; B, $S$. mutans serotype $a ; \mathrm{C}, S$. mutans serotype $b ; \mathrm{D}, S$. mutans serotype $c$. Arrows indicate the positions of standard reference proteins (sizes shown in $\mathrm{kDal}$ ).

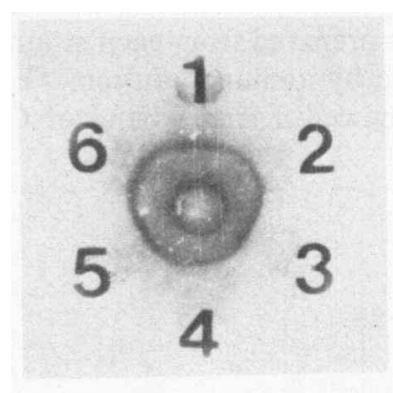

Fig. 3. Immunodiffusion of different ECP fractions against whole anti-S. sanguis ESA serum. Wells 1 , 2, 3, 4, 5 and 6 contained, respectively, purified ECP from $S$. sanguis OMZ9 and from $S$. mutans serotypes $a, b, c, d$, and $e$.

material (Fig. 2) for all antigens tested. The molecular weight of the ECP antigens was estimated by SDS-PAGE as approximately 60000 for all strains.

In immunodiffusion tests, ECP antigens from all the strains reacted with anti-S. sanguis ESA serum to give a single common precipitin line (Fig. 3). Absorption of anti-ESA IgG with $S$. sanguis ECP abolished the precipitin reaction with all ECP antigens. However, the ECP antigens did not react with either $S$. sanguis WEA antiserum absorbed with ESA or sheep antirabbit IgG serum. All these results are in favour of total identity of the ECP antigens derived from all oral strains and confirm their monomeric nature.

\section{Biochemical characterization of the ECP antigens}

Amino acid analysis of the ECP antigens isolated from the different bacterial strains revealed a mixture of the common amino acids except methionine, which was not detected, and tryptophan, which was destroyed during hydrolysis (Table 1). The amino acid composition of the ECP 
Table 1. Amino acid and amino sugar composition of the ECP antigens derived from the different bacterial strains

\begin{tabular}{|c|c|c|c|c|c|c|c|c|c|c|}
\hline \multirow[b]{3}{*}{ Amino acid } & \multicolumn{10}{|c|}{ Number of residues per mol* } \\
\hline & \multirow[b]{2}{*}{ S. sanguis } & \multicolumn{7}{|c|}{$S$. mutans serotype: } & \multirow[b]{2}{*}{ L. salivarius } & \multirow[b]{2}{*}{ A. viscosu } \\
\hline & & $a$ & $b$ & $c$ & $d$ & $e$ & $f$ & $g$ & & \\
\hline Lysine & 33 & 29 & 29 & 32 & 32 & 31 & 30 & 31 & 32 & 31 \\
\hline Histidine & 11 & 8 & 8 & 12 & 8 & 7 & 9 & 13 & 9 & 9 \\
\hline Arginine & 14 & 11 & 12 & 13 & 12 & 10 & 14 & 17 & 14 & 12 \\
\hline Aspartic acid & 41 & 42 & 42 & 38 & 44 & 40 & 43 & 40 & 44 & 47 \\
\hline Threonine & 45 & 44 & 42 & 47 & 45 & 39 & 43 & 42 & 46 & 42 \\
\hline Serine & 44 & 44 & 43 & 42 & 46 & 44 & 46 & 44 & 47 & 42 \\
\hline Glutamic acid & 44 & 55 & 56 & 53 & 47 & 53 & 52 & 44 & 44 & 49 \\
\hline Proline & 39 & 43 & 43 & 40 & 40 & 41 & 40 & 41 & 42 & 48 \\
\hline Glycine & - & - & - & - & - & - & - & - & - & - \\
\hline Alanine & 34 & 43 & 40 & 42 & 39 & 39 & 36 & 33 & 37 & 36 \\
\hline Half cystine & 17 & 14 & 14 & 11 & 14 & 12 & 12 & 10 & 11 & 13 \\
\hline Valine & 41 & 47 & 42 & 43 & 42 & 43 & 45 & 44 & 43 & 47 \\
\hline Methionine & - & - & - & - & - & - & - & - & - & - \\
\hline Isoleucine & 14 & 13 & 14 & 13 & 15 & 21 & 14 & 15 & 14 & 17 \\
\hline Leucine & 26 & 26 & 28 & 24 & 26 & 32 & 27 & 27 & 27 & 31 \\
\hline Tyrosine & 11 & 5 & 7 & 6 & 7 & 6 & 9 & 10 & 8 & 7 \\
\hline Phenylalanine & 24 & 23 & 23 & 19 & 24 & 22 & 21 & 21 & 22 & 20 \\
\hline Glucosamine & 12 & 9 & 10 & 10 & 8 & 9 & 10 & 11 & 11 & 10 \\
\hline Galactosamine & 7 & 10 & 9 & 8 & 12 & 13 & 9 & 13 & 8 & 10 \\
\hline
\end{tabular}

* Calculated numbers of residues based on assumed molecular weight of 60000 .

Table 2. Neutral and amino sugar composition of the ECP antigens derived from the different bacterial strains

Sugar composition (percentage of total)

\begin{tabular}{|c|c|c|c|c|c|c|c|c|c|c|}
\hline \multirow[b]{2}{*}{ Sugar(s) } & \multirow[b]{2}{*}{ S. sanguis } & \multicolumn{7}{|c|}{$S$. mutans serotype: } & \multirow[b]{2}{*}{ L. salivarius } & \multirow[b]{2}{*}{ A. viscosus } \\
\hline & & $a$ & $b$ & $c$ & $d$ & $e$ & $f$ & $g$ & & \\
\hline $\begin{array}{c}\text { Neutral } \\
\text { sugars }\end{array}$ & 5 & 5 & 5 & 5 & 5 & 5 & 5 & 5 & 5 & 5 \\
\hline \multirow{2}{*}{$\begin{array}{l}\text { Amino } \\
\text { sugars }\end{array}$} & 4 & 4 & 4 & 4 & 4 & $4 \cdot 5$ & 4. & 5.5 & 4 & 4 \\
\hline & \multicolumn{10}{|c|}{ Sugar composition (molar ratio) } \\
\hline Glucose & 10 & 10 & 10 & 10 & 9 & 9 & 10 & 9 & 10 & 10 \\
\hline Galactose & 2 & 3 & 2 & 3 & 2 & 3 & 3 & 2 & 3 & 3 \\
\hline Mannose & 4 & 3 & 5 & 4 & 5 & 5 & 4 & 3 & 4 & 3 \\
\hline Fucose & 4 & 4 & 3 & 3 & 4 & 3 & 3 & 5 & 4 & 4 \\
\hline Glucosamine & 10 & 8 & 9 & 9 & 6 & 7 & 8 & 9 & 9 & 8 \\
\hline Galactosamine & 6 & 8 & 7 & 7 & 10 & 11 & 8 & 11 & 7 & 8 \\
\hline
\end{tabular}

antigens was characterized by high concentrations of aspartic and glutamic acids, as well as threonine, serine, proline and alanine. Cysteine, measured as cysteic acid, was present at a concentration of only $3 \%$. All samples were characterized by a high level of glycine, probably due to residual residues derived from the glycine/ $\mathrm{HCl}$ buffer used for column regeneration. These values were not further considered for the total amino acid content and are omitted from Table 1.

The neutral carbohydrate content of the ECP antigens in each case was about $5 \%$ as estimated by the anthronermethod (Table 2). From GLC analysis of ECP antigens, glucose, galactose, mannose and fucose were identified in similar molar ratio. ECP antigens also contained about 
$4 \%$ amino sugars which consisted of glucosamine and galactosamine in molar ratio varying between 0.8 to 1.7 .

The UV light absorption spectra of ECP antigens exhibited a maximum absorption at $280 \mathrm{~nm}$, consistent with a $91 \%$ protein content. In all cases, no significant difference appeared between ECP purified from the different strains.

\section{DISCUSSION}

Recently special attention has been given to the extracellular and wall-associated protein antigens of $S$. mutans (Russell \& Lehner, 1978; Russell, 1979; Nesbitt et al., 1980; Russell et al., $1980 a, b$ ), which could play an important role in caries protection studies (Russell et al., $1980 \mathrm{~b}$; Lehner et al., 1980). In a previous report, we described the presence of a protein antigen (ECP) selectively released in the culture media in the exponential phase of growth by $S$. sanguis OMZ9. This antigen appeared to be common to some oral streptococci including representative strains of the seven serotypes of $S$. mutans, as well as a strain of $L$. salivarius and a strain of $A$. viscosus (Schöller et al., 1981). Monospecific antisera to $S$. sanguis ECP antigen was obtained by extensive cross-absorption of the anti-ESA serum with both heat-killed $S$. sanguis cells and WEA fraction. The data from immunodiffusion analysis of ESA obtained from the different oral strains with antisera cross-absorbed with $S$. sanguis showed the presence of only one precipitin band.

Several bacterial protein antigens were studied by PAGE analysis of solubilized immunoprecipitates (Dankert \& Hofstra, 1978; Archer, 1979). However, the resulting protein profiles always showed contamination by some serum albumin.

Recently, Stone et al. (1979) reported the possibility of purifying IgM by dissociating brucella immune complexes. Dissociation of antigen-antibody complexes may yield proteins other than specific antibody, and such contaminant proteins, principally albumin-like proteins, can be eliminated by an additional gel filtration step. To overcome contamination by non-specific serum proteins, we used only the IgG fraction obtained after protein A-Sepharose chromatography. The existence of a single precipitin band in ID analysis of ESA with absorbed antisera, and the possibility of easily dissociating the antigen-antibody complexes, led us to purify the ECP antigens from crude ESA fractions obtained from the different oral strains.

Maximal dissociation of the immune complexes was obtained by SDS as judged by PAGE analysis. A high concentration of the ionic detergent SDS is known to interfere with antigenantibody reaction in immunochemical techniques such as immunodiffusion or immunoelectrophoresis (Bjerrum \& Lundahl, 1976). However, SDS at concentrations lower than $0 \cdot 2 \%$ did not affect the activities of some bacterial enzymes (Owen \& Doherty, 1979) and has been used previously for immunoprecipitation experiments to determine antibodies against free lipoprotein of the $E$. coli outer membranes (Inouye et al., 1976); the method appeared to be very specific.

In our study, there were two consequences of the step that involved the 50-fold dilution of the dissociated immunoprecipitates. Firstly, the initial SDS concentration was reduced to $0.01 \%$, which did not affect the interactions between the rabbit IgG and the anti-rabbit globulin immunosorbant. Secondly, the protein concentration in the solution was too low for immediate formation of antibody-antigen complexes.

Starting with the crude mixture of extracellular antigens, the ECP antigen was purified to homogeneity, as demonstrated by SDS-PAGE, by chromatography on an anti-rabbit IgG immunosorbant which removed rabbit IgG. ECP antigen recovered from the column was also immunologically homogeneous since immunodiffusion showed that ECP antigen reacted with both total or absorbed anti-ESA IgG to give a single precipitin line.

ECP antigens purified by affinity chromatography from $S$. sanguis, the seven serological groups of $S$. mutans, and individual strains of $L$. salivarius and A. viscosus, were identical as judged by PAGE analysis and by immunodiffusion. The apparent molecular weight of the ECP antigen determined by SDS-PAGE, was approximately 60000 , regardless of the strain from which it was isolated. Positive cross-reaction of the different ECP antigens against anti-S. sanguis ESA or absorbed anti-ESA serum established the identity of ECP antigens from the 
organisms tested. These results were supported by analysis of the amino acid and sugar composition of the different ECPs.

Another extracellular protein, antigen II, was described by Russell et al. (1980a) with a molecular weight of 48000 and an acidic amino acid composition similar to that of ECP antigen, but antigen II differs from ECP in several respects. It is reported to be protease resistant, whereas ECP antigen is protease sensitive (Schöller et al., 1981). Antigen II is also associated with cell wall of only some $S$. mutans, while the ECP antigen seems to be secreted by all bacteria tested; however, it may be present in undetectable amounts on the bacterial cell surface (Schöller et al., 1981).

The presence of such a widely distributed antigen among oral bacteria may be of great importance for future caries protection studies. Recently, however, some $S$. mutans antigens were reported to cross-react with human heart tissue (Russell, 1979; Hughes et al., 1980), and a further comparison of the ECP antigen and human heart tissue antigens will be necessary before it could be used in human vaccination.

We thank Mrs A. Pini for expert technical assistance.

\section{REFERENCES}

ARCHER, D. B. (1979). Immunoprecipitation of Triton X-100-solubilized Mycoplasma mycoides proteins. Journal of General Microbiology 115, 111-116.

BJERRUM, O. J. \& LUNDAHL, P. (1976). Detergent-containing gels for immunological studies of solubilized erythrocyte membranes components. In A Manual for Quantitative Immunoelectrophoresis, pp. 139-143. Edited by N. M. Axelsen, J. Krohll \& B. Weeke. Oslo, Bergen, Tromsø: Universitets Forlaget.

Bratthall, D. (1970). Demonstration of five serological groups of Streptococcus strains, resembling Streptococcus mutans. Odontologisk revy 21, 143-152.

Brown, T. A. \& BleiweIS, A. S. (1979). Chemical, immunological and structural studies of the cross reactive antigens of Streptococcus mutans AHT and B12. Infection and Immunity 24, 326-336.

Burgess, T. E. \& EDwards, J. R. (1973). Chemical characterization of a cell wall antigen from Streptococcus mutans FA-1. Infection and Immunity 8, 491493.

Carlsson, J. (1972). Nutritional requirements of Streptococcus sanguis. Archives of Oral Biology 17, 1327-1332.

DANKERT, J. \& HofSTRA, H. (1978). Antibodies against outer membrane proteins in rabbit antisera prepared against Escherichia coli O26 K60. Journal of General Microbiology 104, 311-320.

Davis, B. J. (1964). Disc electrophoresis. II. Method and application to human serum proteins. Annals of the New York Academy of Sciences 121, 404-427.

Ey, P. L., Prowse, S. J. \& Jenkin, C. R. (1978). Isolation of pure $\mathrm{IgG}_{1}, \mathrm{IgG}_{2}$ and $\mathrm{IgG}_{2 \mathrm{~b}}$ immunoglobulins from mouse serum using protein A-Sepharose. Immunochemistry 15, 429-436.

Hamada, S. \& Slade, H. D. (1980). Biology, immunology and cariogenicity of Streptococcus mutans. Microbiological Reviews 44, 331-384.

Hughes, M., Marchardy, S. M., Sheppard, A. J. \& WoODS, N. C. (1980). Evidence for an immunological relationship between Streptococcus mutans and human cardiac tissue. Infection and Immunity 27, 576-588.

Iacono, V. J., Taubman, M. A., Smith, D. J. \& Levine,
M. J. (1975). Isolation and immunochemical characterization of the group-specific antigen of Streptococcus mutans 6715 . Infection and Immunity 11, 117128.

Inouye, S., Takeiski, K., De Martini, M., HiroshiMA, A. \& INOUYE, M. (1976). Lipoprotein from the outer membrane of Escherichia coli: purification, paracrystallization, and some properties of its free form. Journal of Bacteriology 127, 555-563.

Kelstrup, J. \& Funder-NiELSEN, I. D. (1974). Adhesion of dextran to Streptococcus mutans. Journal of General Microbiology 81, 485-489.

KURAMITSU, H. K. \& INGERSOLL, L. (1978). Interaction of glucosyltransferases with the cell surface of Streptococcus mutans. Infection and Immunity 20, $652-659$.

Lehner, T., Russell, M. W. \& CALdWell, J. (1980). Immunization with a purified protein from Streptococcus mutans against dental caries in Rhesus monkeys. Lancet i, 995-996.

MCCABE, M. M. \& SMITH, E. E. (1973). Origin of the cell associated dextransucrase of Streptococcus mutans. Infection and Immunity 7, 829-838.

MORRIS, D. L. (1948). Quantitative determination of carbohydrate with Dreywood's anthrone reagent. Science 107, 254-258.

Mukasa, H. \& Slade, H. D. (1973). Structure and immunological specificity of the Streptococcus mutans group $b$ cell wall antigen. Infection and Immunity 7, 578-585.

Nesbitt, W. E., Staat, R., Rosan, B., Taylor, K. G. \& DOYLE, R. J. (1980). Association of protein with the cell wall of Streptococcus mutans. Infection and Immunity 28, 118-126.

OUCHTERLONY, O. (1958). Diffusion in gel methods for immunological analysis. Progress in Allergy 5, 1-19.

OWEN, P. \& DOHERTY, H. (1979). Immunochemical analysis of Triton X100 insoluble residues from Micrococcus lysodeikticus membranes. Journal of Bacteriology 140, 881-887.

Perch, B., KJems, E. \& Ravn, T. (1974). Biochemical and serological properties of Streptococcus mutans from various human and animal sources. Acta patho- 
logica et microbiologica scandinavica, section B, 82 , 357-370.

Russell, M. W. \& LeHNER, T. (1978). Characterization of antigens extracted from cells and culture fluids of Streptococcus mutans serotype $c$. Archives of Oral Biology 23, 7-15.

Russell, M. W., Bergmeier, L. A., Zanders, E. D. \& LeHNER, T. $(1980 a)$. Protein antigens of Streptococcus mutans. Purification and properties of a double antigen and its protease-resistant component. Infection and Immunity 28, 486-493.

Russell, M. W., Challacombe, S. J. \& Lehner, T. $(1980 b)$. Specificity of antibodies induced by Streptococcus mutans during immunization against dental caries. Immunology 40, 97-106.

RuSSELL, R. R. B. (1979). Wall-associated protein antigens of Streptococcus mutans. Journal of General Microbiology 114, 109-115.

Schöller, M., Klein, J. P., \& Frank, R. M. (1981).
Common antigens of streptococcal and non streptococcal oral bacteria: immunochemical studies of extracellular and cell-wall associated antigens from Streptococcus sanguis, Streptococcus mutans, Lactobacillus salivarius and Actinomyces viscosus. Infection and Immunity 31, 52-60.

Stone, J. S., Patterson, J. M. \& Phillips, P. (1979). Isolation and purification of bovine IgM by dissociating immunoglobulin-Brucella complexes. Journal of Immunological Methods 31, 379-387.

WEBER, K. \& OSBORN, M. (1969). The reliability of molecular weight determination by dodecyl sulphate polyacrylamide gel electrophoresis. Journal of Biological Chemistry 244, 4406-4412.

Wetherell, J. R. \& Bleiweis, A. S. (1978). Antigens of Streptococcus mutans. Isolation of a serotype-specific and a cross-reactive antigen from walls of strain V.100 (serotype $e$ ). Infection and Immunity 19, 160 169. 